\title{
Quitting smoking and utilization of smoking cessation services in Jordan: a population-based survey
}

\author{
M. Jaghbir,' S. Shareif ${ }^{7}$ and M. Ahram²
}

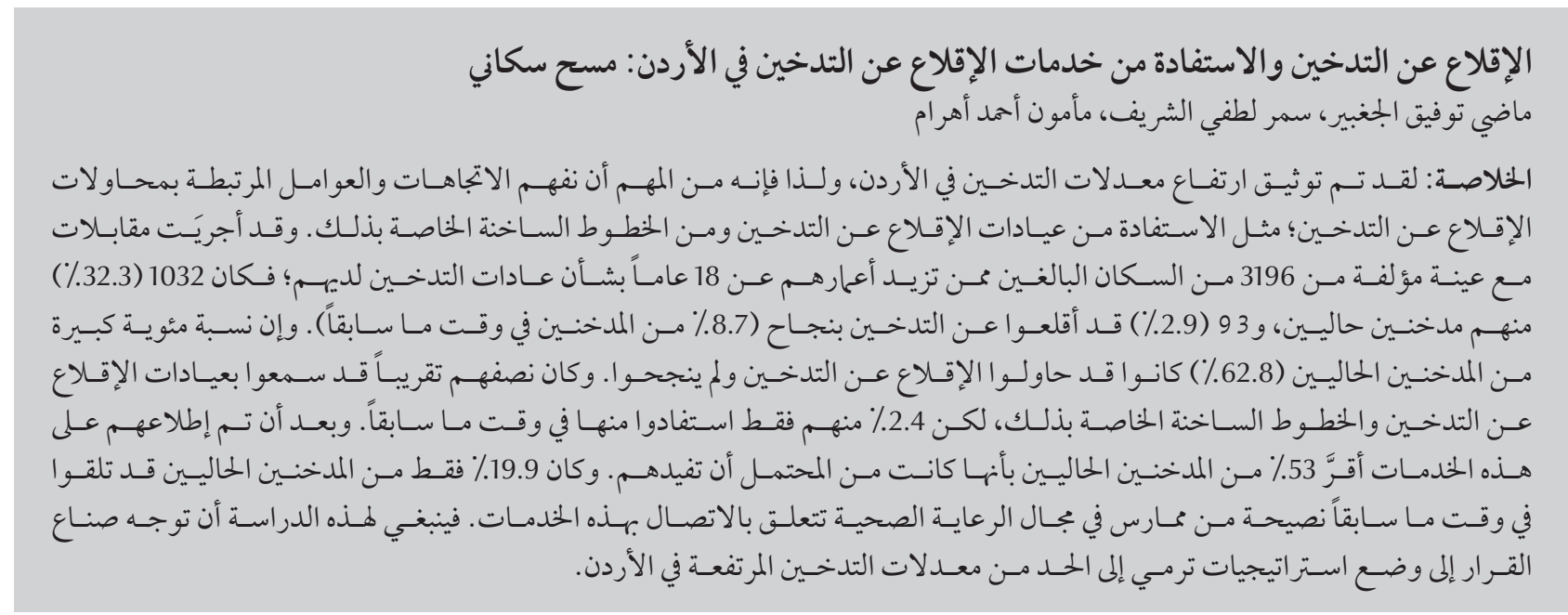

ABSTRACT Increasing rates of smoking in Jordan have been documented. It is therefore important to understand the trends and factors associated with attempts to quit smoking, such as the utilization of smoking cessation clinics and hotlines. A population sample of 3196 adults aged 18+ years were interviewed about their smoking habits; 1032 (32.3\%) were current smokers and 93 (2.9\%) had successfully quit smoking (8.7\% of ever-smokers). A high percentage of current smokers $(62.8 \%)$ had tried, unsuccessfully, to quit smoking. Almost half of them had heard of smoking cessation clinics and hotlines, but only $2.4 \%$ had ever utilized them. After being informed about these services, $53.0 \%$ of current smokers agreed that they were likely to utilize them. Only $19.9 \%$ of current smokers had ever received advice from a health-care practitioner about contacting these services. The study should guide decision-makers on strategies to reduce the high smoking rates in Jordan.

Arrêt de la consommation du tabac et recours aux services de sevrage tabagique en Jordanie : enquête en population

RÉSUMÉ L'augmentation des taux de tabagisme en Jordanie est avérée. II est par conséquent important de comprendre les tendances et les facteurs associés aux tentatives d'arrêt de la consommation de tabac, tels que le recours à des cliniques de sevrage tabagique et aux services d'écoute téléphonique. Un échantillon de population de 3196 adultes âgés de 18 ans et plus a été interrogé sur les habitudes de consommation de tabac ; 1032 (32,3\%) étaient des consommateurs actifs et 93 (2,9\%) avaient réussi à arrêter de fumer (8,7 \% d'adultes ayant déjà fumé). Un fort pourcentage de fumeurs actifs $(62,8 \%)$ avait essayé, sans succès, d'arrêter. Près de la moitié d'entre eux avait entendu parler des cliniques de sevrage tabagique et des services d'écoute téléphonique, mais seuls 2,4 \% les avaient déjà utilisés. Après avoir été informés à propos de ces services, 53,0 \% des fumeurs actifs convenaient qu'il était probable qu'ils les utilisent. Seuls 19,9\% des fumeurs actifs avaient déjà reçu des conseils d'un professionnel de santé les incitant à contacter ces services. La présente étude devrait orienter les décisionnaires sur les stratégies visant à réduire les taux élevés de consommation de tabac en Jordanie.

${ }^{2}$ Department of Family and Community Medicine; ${ }^{2}$ Department of Physiology and Biochemistry, Faculty of Medicine, University of Jordan, Amman, Jordan (Correspondence to M. Jaghbir:jaghbirm@yahoo.com; mjaghbir@ju.edu.jo).

Received: 16/01/14; accepted: 14/04/14 


\section{Introduction}

Numerous studies have reported a substantial health benefit of quitting smoking. For example, similar mortality rates have been documented between those who quit cigarette smoking and those who have never smoked $(1,2)$. The benefits of quitting reach beyond improvements in individuals' own health and quality of life; Parrott and Godfrey have shown that there are major reductions in the cost of health care, with consequent savings for the national gross domestic product of countries (3). As a result, a growing number of countries have campaigned to reduce the number of smokers and are reporting higher proportions of ex-smokers than smokers (4). The United States of America (USA), as an example, has successfully reduced the prevalence of cigarette smoking among adults from $42.4 \%$ to $19.3 \%$ between 1965 and 2010, in part due to an increase in the number of those who have quit smoking (5).

Both older and more recent surveys have indicated a high prevalence of smoking among Jordanians, in particular among males, who have a smoking rate as high as 55\% (6-8). This correlates well with the rate of lung cancer in Jordan, which ranks second among all cancers in males (9). In the current study, we utilized data from a national survey of knowledge, attitudes and practices (KAP) towards cancer prevention and care in Jordan based on a sample representing the Jordanian population. Our analyses attempted to offer a deeper understanding of attempts to quit smoking by Jordanians, their knowledge of cessation clinics and hotlines and their previous and potential utilization of these services. The role of health-care providers is critical for advising patients and persuading smokers to quit. We therefore investigated whether smokers had ever been advised by a health-care provider to quit smoking. It was hoped that the data generated would inform efforts to promote smoking cessation in Jordan.

\section{Methods}

\section{Study design}

This was a quantitative, crosssectional, descriptive survey. Data collection spanned 2 months from 24 January to 19 March 2011. The survey consisted of 10 sections starting with a section about demographic characteristics. One section enquired about the lifestyle of participants including smoking habits and quitting patterns among smokers as well as their knowledge, attitude and practice towards smoking cessation clinics and hotlines, which was the focus of this study.

\section{Participants}

The KAP survey sample was based on the 2004 Jordan Population and Housing Census as the sampling frame. The sampling frame was stratified by governorate, major cities (each city with a population of more than 100000 was considered a stratum, i.e. 6 cities) and other urban and other rural areas. A 3-stage sampling procedure was employed. First, blocks were selected systematically as primary sampling units (PSUs) with a probability proportional to the size of the PSU. In the second stage, a fixed number of 15 households were selected as final sampling units in each PSU, resulting in a sample size of about 4500 households. In the third stage, random selection of individual interviewees from each household was carried out using Kish tables (10). The final sample size in the KAP survey was 3196 participants (a response rate of 93\%): 1647 males and 1549 females. The demographic distribution of the whole interviewed sample are shown in our earlier paper (8). The number of current smokers on which this report is based was 1032 .

\section{Instrument}

A structured questionnaire was designed by a national advisory committee that consisted of research experts from different research, clinical and academic institutions in Jordan. The design of the survey was based on international references/tools that were used as a guide to the development of the questionnaire and to ensure appropriate themes and adaptation to the local context. Face-to-face interviews were conducted in interviewees' households and took an average of 30 minutes to complete. Verbal informed consent was obtained; agreement to host interviews in the participants' house is a culturally appropriate method to obtain consent in Jordan.

A pilot study was conducted to test the survey tool, sampling technique, survey methods and interviewers' level of work. The pilot study spanned a day and was carried out in one area in the capital city, Amman. The pilot sample consisted of 56 randomly selected subjects. Following the pilot, a 2-day review session was conducted and resulted in implementation of minor modifications.

\section{Measures}

Respondents were first asked if they considered themselves as non-smokers, current smokers or ex-smokers. Those who described themselves as smokers were then asked whether they had tried to quit smoking or not, whether they had heard about smoking cessation clinics and whether they had ever utilized them. After the smokers had been informed about the availability of smoking cessation clinics they were asked about the possibility of their consulting one in the future. The latter were measured on a 4-point Likert scale, with scores ranging from very likely to very unlikely. Then they were asked whether any physician or health-care provider had ever suggested these services to them in the previous 12 months to help them to quit smoking. 


\section{Data collection}

Data collection was carried out in the 3 regions of Jordan (North, Middle and South). The face-to-face interviews were conducted by 18 trained teams. Each team consisted of 3 data collectors, 1 controller, 1 field supervisor and 1 driver. The controllers and supervisors conducted spot checks by randomly visiting some sampled households. In order to facilitate data collection, each interviewing team was assigned a number of blocks in the sample area. Interviewers made repeated attempts to obtain the responses of eligible respondents by calling back to interview respondents who were not home at the time of the first visit or by attempting to persuade respondents who were reluctant to be interviewed.

\section{Data processing and analysis}

Data entry using Oracle software started 1 week after the initiation of data collection. After editing and cleaning, the data were exported to SPSS, version 17.0. SPSS was used to run univariate and bivariate analyses to describe all the survey variables. As most of the variables in the study were measured on a nominal and/ or ordinal level, descriptive statistics were used to describe the basic features of the data. Responses to questions were analysed using the chi-squared and/or Pearson correlation coefficients when comparing sociodemographic groups or ranked data respectively.

\section{Results}

Of the 3196 participants interviewed about their smoking habits in the main KAP survey 2071 (64.8\%) reported that they had never smoked, 1032 (32.3\%) were current smokers and only93 (2.9\%) were ex-smokers. The ex-smokers therefore represented $8.7 \%$ of ever-smokers.

\section{Demographic characteristics}

The demographic characteristics of the 1032 current smokers are shown on
Table 1. Current smokers were mainly males $(87.6 \%)$ and the majority were young and middle-aged adults (28.6\%, $32.6 \%$ and $24.2 \%$ respectively). Individuals with intermediate education (58.5\%) constituted the majority of current smokers compared with those with lower (16.2\%) and higher (25.4\%) educational levels. Current smokers were also mainly within the low (48.5\%) and intermediate (37.8\%) income groups rather than the higher income group (13.1\%).

\section{Attempts to quit smoking}

Self-reported current smokers were asked if they had ever attempted to quit smoking. A considerable proportion of them $(62.8 \%)$ had attempted to quit but had failed to do so. This compares with 384 individuals (37.2\%) who had never tried to quit. There were no significant associations between attempting to quit smoking and sex, age or income. However, a significantly higher proportion of those with intermediate educational level had never tried to quit smoking $(41.6 \%)$ in contrast to those with lower (31.7\%) and higher (30.9\%) educational status $(P=0.003)$ (Table 2).

\section{Potential utilization of smoking cessation clinics and hotlines}

Current smokers were asked about their knowledge of smoking cessation clinics or hotlines before this survey. Approximately half of them (50.6\%) had never heard of such services. Males (50.6\%) had significantly better knowledge of smoking cessation clinics or hotlines than did females $(41.4 \%)(P=0.044)$ (Table 3 ). As for age, although there was no significant difference among the age groups $(P=0.065)$, a significant trend towards increasing knowledge with increasing age $(r=0.09 ; P=0.006)$ was found. In addition, there was a significant association of knowledge with better levels of education $(P<0.001)$ and income $(P<0.001)$. Only 25 current smokers $(2.4 \%)$ had ever called a smoking cessation clinic or hotline, with no significant associations by sex, education, age or income (Table 3). Interestingly, a significant association was found between attempting to quit

\begin{tabular}{lcc}
\hline Table 1 Participants' demographic characteristics $(\boldsymbol{n}=\mathbf{1 0 3 2})$ & \\
Characteristic & No. & \\
Sex & & 87.6 \\
$\quad$ Male & 904 & 12.4 \\
$\quad$ Female & 128 & \\
Age (years) & & 28.6 \\
18-29 & 295 & 32.6 \\
$30-39$ & 336 & 24.2 \\
$40-49$ & 250 & 8.0 \\
$50-59$ & 83 & 6.6 \\
$60+$ & 68 & 16.2 \\
Education & 167 & 58.5 \\
Elementary or less & 604 & 25.4 \\
Preparatory to high school & 262 & \\
Diploma and above & & 48.5 \\
Monthly income (JD) & \\
$<300$ & 501 & 37.8 \\
300-599 & 390 & 13.1 \\
$600+$ & 135 & \\
\hline
\end{tabular}

${ }^{a} 6$ respondents refused to declare their income. 


\begin{tabular}{|c|c|c|c|c|}
\hline \multirow[t]{3}{*}{ Variable } & \multicolumn{4}{|c|}{ Ever tried to quit smoking } \\
\hline & \multicolumn{2}{|c|}{ No } & \multicolumn{2}{|c|}{ Yes, but failed } \\
\hline & No. & $\%$ & No. & $\%$ \\
\hline Total & 384 & 37.2 & 648 & 62.8 \\
\hline \multicolumn{5}{|l|}{ Sex } \\
\hline Male & 329 & 36.4 & 575 & 63.6 \\
\hline \multirow[t]{2}{*}{ Female } & 55 & 43.0 & 73 & 57.0 \\
\hline & \multicolumn{4}{|c|}{$\chi^{2}=2.08 ; P=0.090$} \\
\hline \multicolumn{5}{|l|}{ Age (years) } \\
\hline $18-29$ & 110 & 37.2 & 186 & 62.8 \\
\hline $30-39$ & 108 & 32.1 & 228 & 67.9 \\
\hline $40-49$ & 106 & 42.4 & 144 & 57.6 \\
\hline $50-59$ & 35 & 42.2 & 48 & 57.8 \\
\hline \multirow[t]{2}{*}{$60+$} & 25 & 36.8 & 43 & 63.2 \\
\hline & \multicolumn{4}{|c|}{$\chi^{2}=7.46 ; P=0.114(r=-0.04 ; P=0.265)$} \\
\hline \multicolumn{5}{|l|}{ Education } \\
\hline Elementary or less & 53 & 31.7 & 114 & 68.3 \\
\hline Preparatory to high school & 251 & 41.6 & 352 & 58.4 \\
\hline \multirow[t]{2}{*}{ Diploma and above } & 81 & 30.9 & 181 & 69.1 \\
\hline & \multicolumn{4}{|c|}{$\chi^{2}=11.46 ; P=0.003(r=0.02 ; P=0.455)$} \\
\hline \multicolumn{5}{|l|}{ Monthly income (JD) } \\
\hline$<300$ & 177 & 35.3 & 324 & 64.7 \\
\hline $300-599$ & 147 & 37.3 & 243 & 62.3 \\
\hline \multirow[t]{2}{*}{$600+$} & 58 & 43.0 & 77 & 57.0 \\
\hline & \multicolumn{4}{|c|}{$\chi^{2}=2.71 ; P=0.258(r=-0.05 ; P=0.112)$} \\
\hline
\end{tabular}

${ }^{a} 6$ respondents refused to declare their income.

smoking and knowledge of smoking cessation clinics or hotlines $\left(\chi^{2}=7.035\right.$; $P=0.005)$, but not the actual practice of utilizing them $\left(\chi^{2}=3.268 ; P=0.051\right)$ (detailed data not shown). In addition, the practice of calling a smoking cessation clinic or hotline did not show any trend with age $(r=0.001 ; P=0.980)$, education $(r=0.03$; $P=0.392)$ or income $(r=-0.007 ; P=0.815)$.

After informing them about the existence of smoking cessation clinics and hotlines, we assessed the intention of smokers to utilize these services in the future; $53.0 \%$ of current smokers agreed that they were likely or very likely to do so. There was no significant difference by sex in intention to use services $(P=0.499)$. However, younger individuals were more likely than older smokers to agree that they would seek help from a cessation clinic $(P<$ $0.001)$ (Table 4). A significant trend was also observed between decreasing age and the likelihood of calling a cessation clinic $(r=0.13 ; P<0.001)$. Significant differences across the 3 income groups were noted, whereby the likelihood of calling a smoking cessation clinic was lowest at the highest income $(43.0 \%)$ in comparison with $52.8 \%$ and $56.4 \%$ for the low- and middle-income levels, respectively $(P$ $<0.001)$. Despite the lack of a significant trend between increasing education and the likelihood to call these services $(P=0.076)$, individuals with the highest educational level (43.1\%) were significantly less likely to utilize such services than those in the low (53.9\%) and intermediate (56.9\%) educational levels $(P=0.011)$.
A correlation was found between attempting to quit smoking and the likelihood of calling a smoking cessation clinic or hotline $(r=-0.207 ; P<0.001)$ (Table 4).

\section{Role of health-care providers}

We asked current smokers whether they had ever been advised by a healthcare provider to quit smoking by calling a cessation clinic or hotline. Only 19.9\% of current smokers had ever received any advice to quit smoking (Table 5). There were significant disparities in receiving advice from health-care providers among individuals according to income, educational level and age. More specifically, individuals in the higher income and education categories were more likely to be advised by their physicians to quit smoking than 


\begin{tabular}{|c|c|c|c|c|c|c|c|c|}
\hline \multirow[t]{3}{*}{ Variable } & \multicolumn{4}{|c|}{$\begin{array}{c}\text { Ever heard of a smoking cessation clinic or } \\
\text { hotline }\end{array}$} & \multicolumn{4}{|c|}{ Ever called a smoking cessation clinic or hotline } \\
\hline & \multicolumn{2}{|c|}{ No } & \multicolumn{2}{|c|}{ Yes } & \multicolumn{2}{|l|}{ No } & \multicolumn{2}{|l|}{ Yes } \\
\hline & No. & $\%$ & No. & $\%$ & No. & $\%$ & No. & $\%$ \\
\hline Total & 522 & 50.6 & 510 & 49.4 & 1007 & 97.6 & 25 & 2.4 \\
\hline \multicolumn{9}{|l|}{ Sex } \\
\hline Male & 447 & 49.4 & 457 & 50.6 & 883 & 97.7 & 21 & 2.3 \\
\hline \multirow[t]{2}{*}{ Female } & 75 & 58.6 & 53 & 41.4 & 125 & 96.9 & 4 & 3.1 \\
\hline & \multicolumn{4}{|c|}{$\chi^{2}=4.048 ; P=0.044$} & \multicolumn{4}{|c|}{$\chi^{2}=0.289 ; P=0.382$} \\
\hline \multicolumn{9}{|l|}{ Age (years) } \\
\hline $18-29$ & 168 & 56.9 & 127 & 43.1 & 291 & 98.3 & 5 & 1.7 \\
\hline $30-39$ & 169 & 50.3 & 167 & 49.7 & 326 & 97.0 & 10 & 3.0 \\
\hline $40-49$ & 117 & 46.8 & 133 & 53.2 & 243 & 96.8 & 8 & 3.2 \\
\hline $50-59$ & 40 & 48.2 & 43 & 51.8 & 82 & 98.8 & 1 & 1.2 \\
\hline $60+$ & 28 & 41.2 & 40 & 58.8 & 67 & 98.5 & 1 & 1.5 \\
\hline & \multicolumn{4}{|c|}{$\chi^{2}=8.84 ; P=0.065(r=0.09 ; P=0.006)$} & \multicolumn{4}{|c|}{$\chi^{2}=2.52 ; P=0.642(r=0.001 ; P=0.980)$} \\
\hline \multicolumn{9}{|l|}{ Education } \\
\hline Elementary or less & 96 & 57.5 & 71 & 42.5 & 164 & 98.2 & 3 & 1.8 \\
\hline $\begin{array}{l}\text { Preparatory to high } \\
\text { school }\end{array}$ & 323 & 53.6 & 280 & 46.4 & 589 & 97.7 & 14 & 2.3 \\
\hline Diploma and above & 103 & 39.3 & 159 & 60.7 & 254 & 96.9 & 8 & 3.1 \\
\hline & \multicolumn{4}{|c|}{$\chi^{2}=18.76 ; P<0.001(r=0.13 ; P<0.001)$} & \multicolumn{4}{|c|}{$\chi^{2}=0.75 ; P=0.688(r=0.03 ; P=0.392)$} \\
\hline \multicolumn{9}{|l|}{ Monthly income $(J D)^{a}$} \\
\hline$<300$ & 280 & 55.9 & 221 & 44.1 & 490 & 97.8 & 11 & 2.2 \\
\hline $300-599$ & 183 & 46.9 & 207 & 53.1 & 380 & 97.4 & 10 & 2.6 \\
\hline \multirow[t]{2}{*}{$600+$} & 56 & 41.5 & 79 & 58.5 & 133 & 95.5 & 2 & 1.5 \\
\hline & \multicolumn{4}{|c|}{$\chi^{2}=12.40 ; P=0.002(r=0.11 ; P<0.001)$} & \multicolumn{4}{|c|}{$\chi^{2}=0.55 ; P=0.761(r=-0.007 ; P=0.815)$} \\
\hline
\end{tabular}

${ }^{a} 6$ respondents refused to declare their income.

were individuals with lower income and educational level $(P=0.003$ and $P<$ 0.001 respectively). As for age, younger individuals were less likely to receive advice from their physicians $(P<0.001)$.

\section{Discussion}

We found a high number of current smokers in our survey who had attempted to quit smoking but had failed. Although knowledge of smoking cessation clinics and hotlines existed among half of respondents, it did not translate into action, as less than 3\% had ever utilized them. However, the potential use of these services was indicated by around half of respondents. Furthermore, the role of health-care providers in advising smokers to utilize smoking cessation clinics or hotlines was not only minimal but was also biased towards certain subsets of the population.

The quit rate in the Jordanian population on which this study was based $(2.9 \%$ of the total sample were ex-smokers) was close to the estimated figures in Britain of $1-2 \%$ in the last 40 years and 2-3\% in 2005 (11), but lower those in the USA, which had a success rate of $6.2 \%$ in 2009 (12). However, more of the current smokers (62.8\%) interviewed in Jordan had attempted to quit smoking than those in the USA, where $52.4 \%$ of smokers had made a quit attempt in 2009 (12). Overall, numerous different factors are likely to play important roles in quitting tobacco.
Health concerns were reported to be a common motivational factor to quit smoking in different studies including those in Saudi Arabia and Lebanon (13-15). Another study illustrated the importance of setting a model for children as the primary reason for quitting smoking, rather than the cost or family pressure (13). It would therefore be interesting to investigate further the reasons for attempts to quit smoking or the lack of such attempts. Initially, it seems that cost was unlikely to be a motivational factor to quit smoking among Jordanians, as income level was not associated with attempting to quit smoking. However, this observation could be due to the low price of cigarettes not only in Jordan but also in other 


\begin{tabular}{|c|c|c|c|c|c|c|c|c|}
\hline \multirow[t]{3}{*}{ Variable } & \multicolumn{8}{|c|}{ Likelihood of calling a smoking cessation clinic or hotline } \\
\hline & \multicolumn{2}{|c|}{ Very likely } & \multicolumn{2}{|c|}{ Likely } & \multicolumn{2}{|c|}{ Unlikely } & \multicolumn{2}{|c|}{ Very unlikely } \\
\hline & No. & $\%$ & No. & $\%$ & No. & $\%$ & No. & $\%$ \\
\hline Total & 132 & 12.8 & 415 & 40.2 & 249 & 24.1 & 236 & 22.9 \\
\hline \multicolumn{9}{|l|}{ Sex } \\
\hline Male & 113 & 12.5 & 370 & 40.9 & 219 & 24.3 & 202 & 22.4 \\
\hline \multirow[t]{2}{*}{ Female } & 19 & 15.0 & 45 & 35.4 & 30 & 22.8 & 34 & 26.8 \\
\hline & \multicolumn{8}{|c|}{$\chi^{2}=2.37 ; P=0.499$} \\
\hline \multicolumn{9}{|l|}{ Age (years) } \\
\hline $18-29$ & 47 & 15.9 & 119 & 40.3 & 81 & 27.5 & 48 & 16.3 \\
\hline $30-39$ & 53 & 15.8 & 140 & 41.7 & 62 & 18.5 & 81 & 24.1 \\
\hline $40-49$ & 26 & 10.4 & 93 & 37.2 & 67 & 26.8 & 64 & 25.6 \\
\hline $50-59$ & 2 & 2.4 & 38 & 45.8 & 18 & 21.7 & 25 & 30.1 \\
\hline \multirow[t]{2}{*}{$60+$} & 4 & 5.9 & 25 & 36.8 & 21 & 30.9 & 18 & 26.5 \\
\hline & \multicolumn{8}{|c|}{$\chi^{2}=34.40 ; P<0.001(r=0.13 ; P<0.001)$} \\
\hline \multicolumn{9}{|l|}{ Education } \\
\hline Elementary or less & 17 & 10.2 & 73 & 43.7 & 36 & 21.6 & 41 & 24.6 \\
\hline Preparatory to high school & 83 & 13.5 & 261 & 42.6 & 137 & 22.3 & 132 & 21.5 \\
\hline \multirow[t]{2}{*}{ Diploma and above } & 32 & 12.2 & 81 & 30.9 & 76 & 29.0 & 73 & 27.9 \\
\hline & \multicolumn{8}{|c|}{$\chi^{2}=16.64 ; P=0.011(r=0.06 ; P=0.076)$} \\
\hline \multicolumn{9}{|l|}{ Monthly income $(J D)^{a}$} \\
\hline$<300$ & 56 & 11.2 & 208 & 41.5 & 140 & 27.9 & 97 & 19.4 \\
\hline $300-599$ & 71 & 18.2 & 149 & 38.2 & 74 & 19.0 & 96 & 24.6 \\
\hline \multirow[t]{2}{*}{$600+$} & 5 & 3.7 & 53 & 39.3 & 35 & 25.9 & 42 & 31.1 \\
\hline & \multicolumn{8}{|c|}{$\chi^{2}=33.94 ; P<0.001(r=0.07 ; P=0.038)$} \\
\hline \multicolumn{9}{|l|}{ Ever tried to quit smoking } \\
\hline No & 31 & 23.3 & 117 & 28.3 & 122 & 49.2 & 115 & 48.5 \\
\hline \multirow[t]{2}{*}{ Yes, but failed } & 102 & 76.7 & 297 & 71.7 & 126 & 50.8 & 122 & 51.5 \\
\hline & \multicolumn{8}{|c|}{$\chi^{2}=53.36 ; P<0.001(r=-0.21 ; P<0.001)$} \\
\hline
\end{tabular}

${ }^{a} 6$ respondents refused to declare their income.

countries in the Eastern Mediterranean Region (16). We agree with the suggestions of Abdullah and Husten that increasing the cost of cigarette smoking in developing countries by increasing taxes would have an impact on reducing smoking and increasing the readiness to quit (17). It is worth mentioning that an important barrier to utilizing smoking cessation intervention is the higher cost of tobacco quitting services compared with the price of cigarettes (16). The role of education seems perplexing, as those with intermediate education in our study were less likely to attempt to quit smoking. In a study in the USA, attempting to quit smoking was associated with a higher level of education (12). We also found no significant difference according to sex. This is contrary to what has been shown earlier that females are less likely to quit smoking than males due to higher behavioural dependence (18).

Importantly, we found strong correlations of between attempts to quit and knowledge about smoking cessation clinics/hotlines and the probability of seeking help. . In addition, the likelihood of utilizing these services was higher among those who had made unsuccessful attempts to quit smoking. The importance of such services is illustrated by a study conducted among Jordanian university students, who reported that lack of knowledge on how to quit was a reason for not quitting smoking (19). Two studies, one from the USA and another from Hong Kong, found positive results from smoking cessation support $(20,21)$. Similarly, a multinational cohort study found that lack of assistance to quit was predictive of relapses (22). The success rate of smoking cessation clinics has been variable (23). It is likely that the modest success of these clinics is due to their low recognition by the public. This is exactly the 


\begin{tabular}{|c|c|c|c|c|c|c|}
\hline \multirow[t]{3}{*}{ Variable } & \multicolumn{6}{|c|}{ Referred to cessation clinic or hotline by health-care provider } \\
\hline & \multicolumn{2}{|c|}{ No } & \multicolumn{2}{|c|}{ Yes } & \multicolumn{2}{|c|}{$\begin{array}{l}\text { Have not visited health-care } \\
\text { provider recently }\end{array}$} \\
\hline & No. & $\%$ & No. & $\%$ & No. & $\%$ \\
\hline Total & 680 & 65.9 & 205 & 19.9 & 147 & 14.2 \\
\hline \multicolumn{7}{|l|}{ Sex } \\
\hline Male & 600 & 66.4 & 176 & 19.5 & 128 & 14.2 \\
\hline \multirow[t]{2}{*}{ Female } & 80 & 62.5 & 29 & 22.7 & 19 & 14.8 \\
\hline & \multicolumn{6}{|c|}{$\chi^{2}=0.865 ; P=0.649$} \\
\hline \multicolumn{7}{|l|}{ Age (years) } \\
\hline 18-29 & 207 & 69.6 & 45 & 15.2 & 44 & 14.9 \\
\hline $30-39$ & 229 & 68.2 & 61 & 18.2 & 46 & 13.7 \\
\hline $40-49$ & 150 & 59.8 & 60 & 23.9 & 41 & 16.3 \\
\hline $50-59$ & 56 & 67.5 & 19 & 22.9 & 8 & 9.6 \\
\hline $60+$ & 39 & 57.4 & 21 & 30.9 & 8 & 11.8 \\
\hline & \multicolumn{6}{|c|}{$\chi^{2}=15.97 ; P=0.043$} \\
\hline \multicolumn{7}{|l|}{ Education } \\
\hline Elementary or less & 111 & 66.9 & 19 & 11.4 & 36 & 21.7 \\
\hline Preparatory to high school & 388 & 64.2 & 124 & 20.5 & 92 & 15.2 \\
\hline \multirow[t]{2}{*}{ Diploma and above } & 181 & 69.3 & 61 & 23.4 & 19 & 7.3 \\
\hline & \multicolumn{6}{|c|}{$\chi^{2}=24.19 ; P<0.001$} \\
\hline \multicolumn{7}{|l|}{ Monthly income $(J D)^{a}$} \\
\hline$<300$ & 339 & 67.4 & 84 & 16.7 & 80 & 15.9 \\
\hline $300-599$ & 262 & 67.2 & 77 & 19.7 & 51 & 13.1 \\
\hline \multirow[t]{2}{*}{$600+$} & 78 & 57.4 & 43 & 31.6 & 15 & 11.0 \\
\hline & \multicolumn{6}{|c|}{$\chi^{2}=16.13 ; P=0.003$} \\
\hline
\end{tabular}

${ }^{a} 6$ respondents refused to declare their income.

trend we found, whereby more than half of our survey respondents had not heard about these facilities and only $2.4 \%$ of smokers had ever utilized them. A reason for lack of knowledge could be the existence of only 2 such clinics in the capital, Amman, one of which is government-run and lacks sufficient funding. One solution is to strengthen, integrate and/or increase public knowledge of these services. Other solutions include the integration of counselling into clinical practice including followup and medications, as suggested previously $(17,24)$. In addition, the provision of multiple forms of smoking cessation assistance is needed (25).

Previous studies have highlighted the role of health-care providers in attempts to quit smoking. Recent studies revealed that the role of physicians is vital when it comes to smoking cessation $(26,27)$. According to a Centers for Disease Control report, over 50\% of smokers received advice from their health-care provider to quit smoking (28). In a sample of mostly long-term cancer survivors drawn from the 2000 National Health Interview Survey, $42.3 \%$ of individuals who visited a health-care provider in the previous year reported being asked about their smoking status (29). In addition, twothirds of individuals smoking at the time of diagnosis reported being advised to quit smoking by a health-care provider (30). Unfortunately, in our study, only one-fifth of smokers who had visited any health-care providers had been advised to call a smoking cessation clinic or hotline. It is also unfortunate that younger individuals were less likely to be targeted for advice by health-care providers as this group were more likely to report that they would seek assistance from smoking cessation clinics or hotlines. In a recently published study, $46.7 \%$ of Jordanian physicians were current smokers (31) and, based on a previous study, a high percentage $(81 \%)$ of them smoked in front of their patients (32). Shishani et al. found that Jordanian physicians and nurses lacked knowledge about the addictive effects of smoking (33). Collectively, these data suggest a limited involvement of physicians in advising patients to quit smoking in Jordan. It is interesting to note that Jordanian (33) and Egyptian (34) health-care providers requested 
education and training to increase their knowledge and counselling capabilities in smoking cessation. Previous studies conducted in Saudi Arabia and Jordan found that health education is an effective means of smoking cessation $(15,19)$. This enforces the need to establish educational programmes to promote smoking cessation efforts.

It is important to note that, consistent with other self-report interview methods, individuals may be reluctant to state their views objectively and may provide biased answers that are socially acceptable. However, a major strength of our study was the involvement of a representative sample of the Jordanian population.

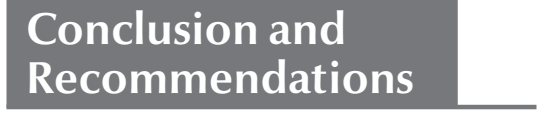

There was a large difference in our study between the proportion of current smokers who wished to quit smoking and those who had successfully quit. It is also important to highlight the missed opportunities for health-care providers to advise smokers to quit. Concerted efforts need to be initiated among the various social and health groups in Jordan, along with government policies to increase knowledge about smoking cessation services among the public and healthcare providers and to support smoking cessation programmes. Income was not associated with desire to quit smoking, which suggests that an increase in the price of tobacco products is warranted.

\section{Acknowledgements}

Funding: This work was supported by the Arab Fund for Economic and Social Development (AFESD). The KAP survey was implemented by King Hussein Institute for Biotechnology and Cancer (KHIBC) under The National Life Science Research and Biotechnology Promotion (LSR/BTP) Initiative in Jordan.

Competing interests: None declared.

\section{References}

1. A Report of the Surgeon General: how tobacco smoke causes disease: the biology and behavioral basis for smoking-attributable disease, 2010. Atlanta (GA): Centers for Disease Control, US Department of Health and Human Services; 2010 (http:// www.surgeongeneral.gov/library/tobaccosmoke/report/ full_report.pdf, accessed 29 May 2014).

2. Doll R, Peto R, Boreham J, Sutherland I. Mortality in relation to smoking: 50 years' observations on male British doctors. BMJ. 2004 Jun 26;328(7455):1519-28. PMID:15213107

3. Parrott S, Godfrey C. Economics of smoking cessation. BMJ. 2004 Apr 17;328(7445):947-9. PMID:15087348

4. Chapman S, MacKenzie R. The global research neglect of unassisted smoking cessation: causes and consequences. PLoS Med. 2010 Feb;7(2):e1000216. PMID:20161722

5. Smoking and tobacco use: trends in current cigarette smoking among high school students and adults, United States, 1965-2010. Atlanta (GA): Centers for Disease Control, US Department of Health and Human Services; 2010 (http://www. cdc.gov/tobacco/data_statistics/tables/trends/cig_smoking, accessed 29 May 2014).

6. Mackay J, Eriksen M. The tobacco atlas. Geneva, Switzerland: World Health Organization; 2002.

7. Belbeisi A, AI Nsour M, Batieha A, Brown DW, Walke HT. A surveillance summary of smoking and review of tobacco control in Jordan. Global Health. 2009;5:18. PMID:19951428

8. Jaghbir M, Shreif S, Ahram M. Pattern of cigarette and waterpipe smoking in the adult population of Jordan. East Mediterr Health J. 2014;20. Forthcoming

9. Jordan Cancer Registry. Cancer incidence in Jordan. Ministry of Health; 2009.

10. Kish. Survey Sampling. New York: John Wiley and Sons, Inc.; 1965.

11. West R. Background smoking cessation rates in England, 2006 (http://www.smokinginengland.info/ downloadfile/?type $=$ sts-documents\&src $=6$, accessed 18 June 2014).

12. Centers for Disease Control and Prevention (CDC). Quitting smoking among adults-United States, 2001-2010.
MMWR Morb Mortal Wkly Rep. 2011 Nov 11;60(44):1513-9. PMID:22071589

13. Halpern MT, Warner KE. Motivations for smoking cessation: a comparison of successful quitters and failures. J Subst Abuse. 1993;5(3):247-56. PMID:8312730

14. Chaaya M, Mehio-Sibai A, El-Chemaly S. Smoking patterns and predictors of smoking cessation in elderly populations in Lebanon. Int J Tuberc Lung Dis. 2006 Aug;10(8):917-23. PMID:16898378

15. Saeed AA, Khoja TA, Khan SB. Smoking behaviour and attitudes among adult Saudi nationals in Riyadh City, Saudi Arabia. Tob Control. 1996 Autumn;5(3):215-9. PMID:9035357

16. Heydari G, Talischi F, Mojgani N, Masjedi MR, Algouhmani $\mathrm{H}$, Lando $\mathrm{HA}$, et al. Status and costs of smoking cessation in countries of the Eastern Mediterranean Region. East Mediterr Health J. 2012 Nov;18(11):1102-6. PMID:23301371

17. Abdullah AS, Husten CG. Promotion of smoking cessation in developing countries: a framework for urgent public health interventions. Thorax. 2004 Jul;59(7):623-30. PMID:15223875

18. Bohadana A, Nilsson F, Rasmussen T, Martinet Y. Gender differences in quit rates following smoking cessation with combination nicotine therapy: influence of baseline smoking behavior. Nicotine Tob Res. 2003 Feb;5(1):111-6. PMID:12745512

19. Haddad LG, Malak MZ. Smoking habits and attitudes towards smoking among university students in Jordan. Int J Nurs Stud. 2002 Nov;39(8):793-802. PMID:12379297

20. Abdullah AS, Hedley AJ, Chan SS, Ho WW, Lam TH; Hong Kong Council on Smoking and Health Smoking Cessation Health Centre (SCHC) Steering Group. Establishment and evaluation of a smoking cessation clinic in Hong Kong: a model for the future service provider. J Public Health (Oxf). 2004 Sep;26(3):239-44. PMID:15454590

21. Carlson LE, Taenzer P, Koopmans J, Bultz BD. Eight-year follow-up of a community-based large group behavioral smoking cessation intervention. Addict Behav. 2000 SepOct;25(5):725-41. PMID:11023014

22. Zhou X, Nonnemaker J, Sherrill B, Gilsenan AW, Coste F, West R. Attempts to quit smoking and relapse: factors associated 
with success or failure from the ATTEMPT cohort study. Addict Behav. 2009 Apr;34(4):365-73. PMID:19097706

23. Fiore MC, Novotny TE, Pierce JP, Giovino GA, Hatziandreu EJ, Newcomb PA, et al. Methods used to quit smoking in the United States. Do cessation programs help? JAMA. 1990 May 23-30;263(20):2760-5. PMID:2271019

24. Su TT, Sallehuddin BA, Murniati HH, Swinder J, Al Sadat N, Saimy I. Factors associated with success or failure of quit attempts: a clinical approach for lung cancer prevention. Asian Pac J Cancer Prev. 2012;13(1):175-9. PMID:22502663

25. Insights: smoking in Wisconsin. A series of papers analyzing Wisconsin tobacco use and providing recommendations for action, based on interviews with 6000 Wisconsin residents (Why People Smoke Action Paper No. 1). Madison (WI): University of Wisconsin Center for Tobacco Research and Intervention; 2003 (http://www.ctri.wisc.edu/Publications/ publications/WhyPeopleSmokefl.pdf, accessed 29 May 2014).

26. Saglam L. Investigation of the results of a smoking cessation clinic and the factors associated with success. Turk J Med Sci. 2012;42(3):515-22.

27. Russo AC, Azevedo RC. Factors that motivate smokers to seek outpatient smoking cessation treatment at a university general hospital. J Bras Pneumol. 2010 Sep-Oct;36(5):603-11. PMID:21085826

28. Kruger J, Shaw L, Kahende J, Frank E. Health care providers' advice to quit smoking, National Health Interview Survey, 2000, 2005, and 2010. Prev Chronic Dis. 2012;9:E130. PMID:22814236
29. Sabatino SA, Coates RJ, Uhler RJ, Pollack LA, Alley LG, Zauderer LJ. Provider counseling about health behaviors among cancer survivors in the United States. J Clin Oncol. 2007 May 20;25(15):2100-6. PMID:17513816

30. Blanchard CM, Denniston MM, Baker F, Ainsworth SR, Courneya KS, Hann DM, et al. Do adults change their lifestyle behaviors after a cancer diagnosis? Am J Health Behav. 2003 May-Jun;27(3):246-56. PMID:12751621

31. Shishani K, Nawafleh H, Jarrah S, Froelicher ES. Smoking patterns among Jordanian health professionals: a study about the impediments to tobacco control in Jordan. Eur J Cardiovasc Nurs. 2011 Dec;10(4):221-7. PMID:20826114

32. Merrill RM, Madanat H, Kelley AT, Layton JB. Nurse and physician patient counseling about tobacco smoking in Jordan. Promot Educ. 2008 Sep;15(3):9-14. PMID:18784047

33. Shishani K, Nawafleh H, Sivarajan Froelicher E. Jordanian nurses' and physicians' learning needs for promoting smoking cessation. Prog Cardiovasc Nurs. 2008 Spring;23(2):79-83. PMID:18843829

34. Eldein HN, Mansour NM, Mohamed SF. Knowledge, attitude and practice of family physicians regarding smoking cessation counseling in family practice centers, Suez Canal University, Egypt. J Family Med Prim Care. 2013 Apr;2(2):159-63. PMID:24479071 